Article

\title{
Exposure Assessment for Italian Population Groups to Deoxynivalenol Deriving from Pasta Consumption
}

\section{Carlo Brera *, Valentina Bertazzoni, Francesca Debegnach, Emanuela Gregori, Elisabetta Prantera and Barbara De Santis}

Istituto Superiore di Sanità, Dipartimento di Sanità Pubblica Veterinaria e Sicurezza Alimentare, Reparto OGM e Xenobiotici di origine fungina, Viale Regina Elena, Rome 299-00161, Italy; E-Mails: bertazzonivale@gmail.com (V.B.); francesca.debegnach@iss.it (F.D.); emanuela.gregori@iss.it (E.G.); elisabetta.prantera@gmail.com (E.P.); barbara.desantis@iss.it (B.D.S.)

* Author to whom correspondence should be addressed; E-Mail: carlo.brera@iss.it; Tel.: +39-06-4990-2377; Fax: +39-06-4990-2363 .

Received: 17 October 2013; in revised form: 18 November 2013 / Accepted: 19 November 2013 / Published: 26 November 2013

\begin{abstract}
Four hundred and seventy-two pasta samples were collected from long retail distribution chain sales points located in North, Central and South Italy. Representative criteria in the sample collection were followed in terms of number of samples collected, market share, and types of pasta. Samples were analysed by an accredited HPLC-UV method of analysis. The mean contamination level $(64.8 \mu \mathrm{g} / \mathrm{kg})$ of deoxynivalenol (DON) was in the 95th percentile $(239 \mu \mathrm{g} / \mathrm{kg})$ and 99th percentile $(337 \mu \mathrm{g} / \mathrm{kg})$, far below the legal limit $(750 \mu \mathrm{g} / \mathrm{kg})$ set by Regulation EC/1126/2007, accounting for about one tenth, one third and half the legal limit, respectively. Ninety-nine percent of samples fell below half the legal limit. On the basis of the obtained occurrence levels and considering the consumption rates reported by the Italian official database, no health concern was assessed for all consumer groups, being that exposure was far below the Tolerable Daily Intake (TDI) of $1000 \mathrm{ng} / \mathrm{kg} \mathrm{b.w/day.} \mathrm{Nevertheless,} \mathrm{despite} \mathrm{this,} \mathrm{particular} \mathrm{attention} \mathrm{should} \mathrm{be}$ devoted to the exposure to DON by high consumers, such as children aged 3-5 years, who could reach the TDI even with very low levels of DON contamination.
\end{abstract}

Keywords: deoxynivalenol; pasta; exposure assessment; risk assessment; consumer groups; children; cereals 


\section{Introduction}

Deoxynivalenol (DON) is a natural-occurring mycotoxin produced at pre-harvest stage by several Fusarium species, mainly F.graminearum and F. culmorum [1], and belongs to a wide family of mycotoxins known as trichothecenes. It is also known as vomitoxin due to its strong emetic effects after consumption, because it is transported into the brain where it runs dopaminergic receptors.

Chemically, DON (Figure 1) is a sesquiterpenoid polar organic compound, which belongs to the type $\mathrm{B}$ trichothecenes since it contains carbonyl group in C-8. Its empirical formula is $\mathrm{C}_{15} \mathrm{H}_{20} \mathrm{O}_{6}$. DON is highly hydrosoluble and stable at cooking temperatures $\left(120^{\circ} \mathrm{C}\right)$, and in storage conditions and milling processes $[2,3]$.

Figure 1. Chemical structure of deoxynivalenol (DON).

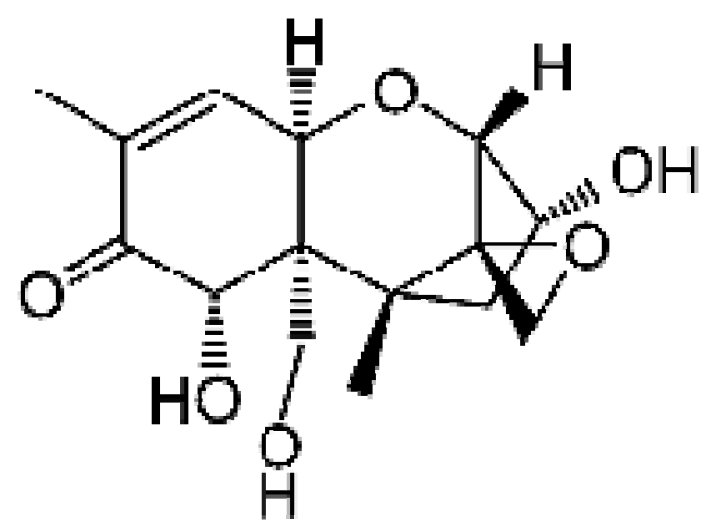

DON is one of the most pervasive mycotoxins that predominantly colonize wheat ears and also corn leaves. Fungi attack mainly occurs in the field before harvest [4].

The optimal range of temperatures for DON production is $21-29{ }^{\circ} \mathrm{C}$ at moisture levels $>20 \%$. DON is considered as a marker for the presence of other mycotoxins such as zearalenone [5].

The fungus has two distinct growth cycles corresponding to mould growth during warm daytime temperatures and toxin production during cool night-time temperatures [6].

Red ear rot caused by $F$. graminearum is favoured by warm wet weather after silking. This plant disease tends to be more risky in conditions of no rotation between subsequent cultivations, and in general when corn or wheat precedes wheat and corn crops respectively as a consequence of the permanence of contamination in the debris. Reduced tillage situations, provides additional elements for an increase of the probability of fungi attack.

To date, all animal species are susceptible to DON in the following order: pigs $>$ mice $>$ rats $>$ poultry $\approx$ ruminants [7]. Differences in metabolism, absorption, distribution, and elimination of DON among animal species might account for this differential sensitivity.

Specifically in swine, DON intake reduces weight gain and hinders animal feeding. At high concentrations (more than $10 \mathrm{ppm}$ ) typical signs are emesis and total feed refusal [8]. In terms of DON bioavailability, sheep and cows show very low rates (10\% for single-doses administered) [9] in contrast with swine where approximately $95 \%$ of the administered dose was recovered as deoxynivalenol [10]. 
Acute exposure of pigs to DON causes abdominal distress, increased salivation, malaise, diarrhea, and emesis $[11,12]$.

DON is detectable also in blood and serum in high amounts immediately after ingestion, but is rapidly cleared from the blood stream.

Although JECFA established that DON is a probable factor for acute pathologies in humans, there is not enough data yet to set an Acute Reference Dose (RfD) [13].

In 1993, IARC classified DON in Group 3, corresponding to not classifiable for its carcinogenicity to humans; in 2002 the Scientific Committee for Food set a tolerable daily intake of $1 \mu \mathrm{g} / \mathrm{kg} \mathrm{bw} / \mathrm{d}$.

In humans, deoxynivalenol causes gastro-intestinal problems, immunosuppression and interferences with reproduction and development [14-18]. DON effects in humans have not yet been widely registered but new evidence that has led to a report of immunotoxicity in humans even at low doses of contamination that could create proteomic changes in human B (RPMI1788) and T (JurkatE6.1) lymphocyte cell lines is currently under consideration. These potential effects are to be considered much more alarming if transferred to the fetus where, according to a Norwegian study, $21 \%$ of the toxin is transferred, with no activation of DON required and a very poor detoxification route. More generally, a correlation between low sanitary quality of cereals and increase of abortions during pregnancy was also noted [19-21].

In vitro studies using human intestinal Caco-2 cells suggested that DON crosses the intestinal mucosa through a para-cellular pathway, though contribution by passive trans-cellular diffusion could not be ruled out $[17,22]$.

From the above, this study provides an evaluation of the exposure to deoxynivalenol deriving from the consumption of pasta by different groups of Italian consumers, with a focus to a very sensitive subgroup such as children.

\subsection{Legislation on DON}

Almost 40 countries have established regulatory limits or guidelines for DON in wheat and other cereal-based products. The guideline levels for cereals and finished cereal products for humans range from 100 to $2000 \mu \mathrm{g} / \mathrm{kg}$, depending on consumer age and stage of processing of the grain [23]; levels in diets for swine, poultry, and cattle range from 500 to $10.000 \mu \mathrm{g} / \mathrm{kg}$ [24].

The European Commission set maximum tolerable limits for DON in food products. EC Regulation $1126 / 2007$ applies to the unprocessed durum wheat and oat $(1750 \mu \mathrm{g} / \mathrm{kg})$, soft wheat $(1250 \mu \mathrm{g} / \mathrm{kg})$ and to milled intermediate products, e.g finished products $(500 \mu \mathrm{g} / \mathrm{kg})$, dry pasta, cereals destined for direct human consumption, such as cereal flour, bran and germ $(750 \mu \mathrm{g} / \mathrm{kg})$ and processed cereal-based baby foods and foods for young children $(200 \mu \mathrm{g} / \mathrm{kg})$ [25]. Currently, no legal limits but only guidance values have been set by the EU Recommendation 576/2006 for complementary and complete feeding stuffs at various levels depending on the animal species susceptibility such as pigs, calves ( $<4$ months), lambs and kids [26].

However, it should be considered that DON contribution to animal origin food products as carried over from feeds is generally negligible since no residues in eggs, milk and edible tissues were found in the literature. It was shown, in fact, that DON is rapidly metabolized by de-epoxydation and glucuronization leading to the formation of reduced toxicity metabolites [27]. 


\subsection{Exposure Assessment by DON in Humans}

Generally, human exposure assessment derived from mycotoxin-contaminated diet is a more and more challenging issue in the worldwide scenario. What is still pending is the real aetiological role of these hazards in the development of pathologies such as cancer or mycotoxin-induced immunodepression diseases or other pathologies not yet related, like autism or celiac disease [28,29].

From the data available in the literature, in humans, the emetic effects of this mycotoxin were firstly described in Japanese men consuming mouldy barley containing Fusarium fungi in 1972 [30,31].

In China, between 1961 and 1985, about 35 outbreaks of acute human illness were reported. The symptoms of nausea, vomiting, diarrhea, abdominal pain, headache, dizziness, and fever were attributed to DON and other trichothecenes contaminated cereals, with at least 7818 victims.

In an outbreak in 1984 in Xingtai County, 94\% persons who ate moldy maize became ill. The range of DON levels was from 3.8 to $93 \mathrm{mg} / \mathrm{kg}$ [13].

DON was detected in all 15 urine samples of female inhabitants of Linxian County and Gejiu, two Chinese high and low, respectively, risk exposure regions for DON and oesophageal cancer, with mean levels of 37 and $12 \mathrm{ng} / \mathrm{mL}$, respectively [32].

In one-year-old Dutch children exposed to DON levels above the Provisional Maximum Tolerable Daily Intake (PMTDI), reductions in body weight and relative liver weight were estimated at 2.2\% and 2.7\% (confidence interval: $0.2 \%-25 \%$ ), respectively [33].

In a study performed in UK, DON was detected in the urine of 296 out of 300 healthy subjects showing a strong association between the cereal intake and urinary DON concentrations $(p<0.0005)$. From a multivariable analysis, wholemeal and white bread as well as other cereal-based food products including pasta were consistently related to urinary DON excretion.

The geometric mean concentrations were 6.55, 9.63, and 13.24 $\mu \mathrm{g}$ DON/day for low-, medium-, and high-cereal intake groups, respectively. Consumption of other grain-based foods such as cereal products and pasta was also significantly associated with urinary DON concentrations [34].

In another study by Hepworth et al., DON exposure assessment was evaluated in a group of pregnant women aged 16-44 from Bradford, UK. The urinary DON was detected in all samples in a range from 0.5 to $116.7 \mathrm{ng} / \mathrm{mg}$ creatinine. From a food questionnaire, bread, particularly chapattis in South Asian women, was the major contributor to DON exposure [35].

In 2003, the study performed by the European Commission within the SCOOP task 3.2.10 revealed that the total intake of DON calculated from data coming from 12 member States ranged from $14.45 \%-46.1 \%$ to $11.3 \%-95.9 \%$ of TDI for adults and children, respectively. The contribution deriving from wheat and derived products accounted for $76 \%-90 \%$. In this study, among foodstuffs, pasta showed a lower rate in the overall contribution to DON intake $(25 \%)$ compared to wheat flour and bread [36].

Analogous results were obtained by Larsen et al. [37] where higher intakes were calculated considering the 95th percentile of consumption data multiplied by the mean DON concentration resulted in an intake very close to or even higher than TDI, with specific emphasis for children and infants.

It should be noted that in another study performed on baby foods in Italy by Pietri et al. in 2004, DON intakes higher than the TDI (121\%) were observed. In this study, a consumption of 100 grams of cereal-based products was considered [38]. 


\section{Occurrence of DON in Wheat Products}

So far, in order to estimate the real amount of DON ingested with human diet, a reliable assessment should be made, taking into account (i) the metabolic pathways of DON leading to the formation of various DON-metabolites, DOM-1, glucuronic-DON, 3-AcOH-DON and 15-AcOH-DON; (ii) the lifecycle of DON from the raw kernel to the finished products such as flour or bread and pasta; and (iii) the frequency and degree of the occurrence of DON contamination levels in the wheat products ingested by the final consumer.

The results obtained in a recent study by Brera et al. [39] showed a significant DON reduction from the caryopsis to cooked pasta, accounting for a mean DON contamination decrease of $78 \%$. Moreover, the overall DON reduction observed from wheat grain to dry pasta was $66 \%$.

Another study conducted by Visconti et al. concluded that the retention level of DON from grains on the market to cooked pasta on the plate can be conservatively assessed at $25 \%$ or less [40].

As far as DON bio-accessibility, a recent in vitro study has demonstrated differences in levels of DON during the child digestion processes, attributable to different typologies of pasta and initial contamination levels [41].

L. González-Osnaya et al. evaluated the occurrence of DON at a rate of $28 \%$ in bread whereas in pasta the occurrence was higher, varying from $9.3 \%$ to $62.7 \%$. The mean content of deoxynivalenol in bread was $42.5 \mu \mathrm{g} / \mathrm{kg}$ while in pasta the content of deoxynivalenol was higher $(137.1 \mu \mathrm{g} / \mathrm{kg})$. The estimated daily intake of deoxynivalenol from the consumption of the mentioned products represented $8.4 \%$ of the tolerable daily intake [42].

Bockhorn et al. analysed 29 pasta samples purchased from retail shops in Berlin in April and May 2001 and were analysed for their content of deoxynivalenol. Ninety percent of the raw samples contained less than $0.5 \mathrm{mg} \mathrm{DON} / \mathrm{kg}$, but three out of 29 samples had contamination of up to $0.84 \mathrm{mg} / \mathrm{kg}$. The amount of DON decreased after cooking, resulting in $60 \%-80 \%$ lower DON levels in the ready to eat products [43].

\section{Results and Discussion}

\subsection{Exposure Assessment}

Exposure of different population groups was calculated by a deterministic approach using the following equation:

$$
\text { EXPOSURE }=\frac{\text { mean contamination }\left(\frac{n g}{g}\right) \times \text { mean consumption }(g)}{\text { weight }(\mathrm{kg})}
$$

As far as the calculation of DON intake derived from only pasta, three different parameters were taken into account: the mean contamination value, the mean consumption rate expressed in grams, and the body weight expressed in $\mathrm{kg}$. The exposure was calculated as $\mathrm{ng} / \mathrm{kg}$ body weight/day. This unit was chosen to compare the resulting values with the TDI of DON that was set by the Scientific Committee for Food at $1000 \mathrm{ng} / \mathrm{kg}$ bw/day [44]. 


\subsection{Occurrence Values}

The statistical description analysis of the obtained results is shown in Tables 1 and 2. The mean $(64.8 \mu \mathrm{g} / \mathrm{kg})$ and median $(35 \mu \mathrm{g} / \mathrm{kg})$ DON values of all samples were far from the legal limit of $750 \mu \mathrm{g} / \mathrm{kg}$.

Ninety-nine percent of samples did not exceed the threshold of $50 \%$ of the legal limit. A percentage of $78.6 \%$ of samples was lower than the limit of quantification $(70 \mu \mathrm{g} / \mathrm{kg})$. Even the DON contamination levels corresponding to the 95 th percentile and 99 th percentile were around $50 \%$ of the legal limit.

The contamination profile of a subgroup of pasta samples $(\mathrm{N}=43)$, namely short shape typology, more commonly consumed by elderly and children but not corresponding to baby foods, showed slight different values for the mean $(101.5 \mu \mathrm{g} / \mathrm{kg})$ that were higher than the overall mean. All the other values, i.e., median, 95th percentile, 99th percentile and the maximum contamination value, overlapped with the overall scenario.

No cluster contamination was observed for a specific brand and generally the contamination was equally distributed among the different brands.

The obtained contamination levels generally confirm previous findings cited before.

Table 1. Descriptive statistics of DON contamination in pasta samples.

\begin{tabular}{cc}
\hline Parameter & Numerical value \\
\hline Number of samples & 472 \\
Samples $<$ LOQ & $371(78.6 \%)$ \\
Samples $\geq$ LOQ & $101(21.4 \%)$ \\
Mean contamination $(\mu \mathrm{g} / \mathrm{kg})$ & $64.8^{*}$ \\
Median contamination $(\mu \mathrm{g} / \mathrm{kg})$ & $35^{*}$ \\
95th percentile of contamination $(\mu \mathrm{g} / \mathrm{kg})$ & 239.4 \\
99th percentile of contamination $(\mu \mathrm{g} / \mathrm{kg})$ & 337.0 \\
MAX contamination $(\mu \mathrm{g} / \mathrm{kg})$ & 385.7 \\
\hline
\end{tabular}

Note: *Mean and median values have been computed assigning to $<$ LOQ results, the value of $\mathrm{LOQ} / 2=35 \mu \mathrm{g} / \mathrm{kg}$.

Table 2. Descriptive statistics of DON contamination in small size pasta samples.

\begin{tabular}{cc}
\hline Parameter & Numerical value \\
\hline Number of samples & 43 \\
Samples $<$ LOQ & $26(60.5 \%)$ \\
Samples $\geq \mathrm{LOQ}$ & $17(39.5 \%)$ \\
Mean contamination $(\mu \mathrm{g} / \mathrm{kg})$ & $101.5^{*}$ \\
Median contamination $(\mu \mathrm{g} / \mathrm{kg})$ & $35^{*}$ \\
95th percentile of contamination $(\mu \mathrm{g} / \mathrm{kg})$ & 279.6 \\
99th percentile of contamination $(\mu \mathrm{g} / \mathrm{kg})$ & 320.9 \\
MAX contamination $(\mu \mathrm{g} / \mathrm{kg})$ & 336.4 \\
\hline
\end{tabular}

Note: * Mean and median values have been computed assigning to $<$ LOQ results, the value of $\mathrm{LOQ} / 2=35 \mu \mathrm{g} / \mathrm{kg}$. 


\subsection{Consumption Rate}

Mean consumption rates of pasta related to specific subgroups of population were taken by the Italian official reference database published by Leclercq in 2009 [45]. The study was conducted randomly selecting households after geographical stratification of the national territory. Food consumption was assessed on three consecutive days through individual estimated dietary records. The study sample encompassed 3323 subjects (1501 males and 1822 females) aged 0.1 to 97.7 years belonging to 1329 households.

In Table 3, mean, 95th percentile and 99th percentile consumption rates for total population, consumers only, children, adolescents, adults and elderly, are reported. For children, the data are reported combining males and females. Vice versa, for adolescents, adults and elderly, a distinction of gender is provided.

The range of consumption rates is between $54.2 \mathrm{~g} / \mathrm{d}$ and $161.7 \mathrm{~g} / \mathrm{d}$ being this latter value the worst in absolute terms since it corresponds to children 3-9.9 years whose body weight is to be considered unfavorable for the intake.

For this reason, the exposure assessment was calculated considering in more detail the status only for children.

Table 3. Mean, 95th percentile* and 99th percentile** of individual daily consumption of pasta in the total population (TP), in consumers only (C) and in males (M) and females (F) of different ages $(\mathrm{g} / \mathrm{d})$.

\begin{tabular}{lccccc}
\hline \multirow{2}{*}{ Category } & & & \multicolumn{3}{c}{ Consumption (g/day) } \\
\cline { 4 - 5 } & & Gender & Mean & 95th percentile & 99th percentile \\
\hline Total population & & 54.2 & 108.7 & 140.1 \\
Consumers only & & 59.5 & 110.7 & 141.9 \\
Children (3-9.9 years) & Total population & & 58.2 & 104.9 & 161.7 \\
& Consumers only & & 59.8 & 104.9 & 161.7 \\
Adolescent (10-17.9 years) & Total population & $\mathrm{M}$ & 63.6 & 128.0 & 133.3 \\
& & $\mathrm{~F}$ & 56.6 & 105.3 & 133.3 \\
& Consumers only & $\mathrm{M}$ & 66.7 & 128.0 & 133.3 \\
& & $\mathrm{~F}$ & 61.0 & 105.3 & 133.3 \\
Adult (18-64.9 years) & Total population & $\mathrm{M}$ & 60.3 & 118.4 & 156.1 \\
& & $\mathrm{~F}$ & 47.7 & 100.0 & 134.8 \\
& Consumers only & $\mathrm{M}$ & 66.0 & 121.6 & 156.9 \\
& & $\mathrm{~F}$ & 53.8 & 102.2 & 137.8 \\
Elderly ( $\geq 65$ years) & Total population & $\mathrm{M}$ & 61.1 & 109.6 & 129.8 \\
& & $\mathrm{~F}$ & 50.7 & 100.6 & 117.4 \\
& Consumers only & $\mathrm{M}$ & 64.3 & 116.5 & 131.2 \\
& & $\mathrm{~F}$ & 54.5 & 110.9 & 121.5 \\
\hline
\end{tabular}




\subsection{Body Weights}

Body weights of children between 3 and 5 years were taken from the WHO official database [46], and between 6-14 years, 15-18 years and over 18 years values as reported from EFSA [47] were considered. In Table 4, the corresponding values are reported.

Table 4. Mean weight $(\mathrm{kg})$ in all groups of population between 3 and $>18$ years.

\begin{tabular}{ccc}
\hline AGE (years) & Boys & Girls \\
\hline 3 & 14.3 & 13.9 \\
4 & 16.3 & 16.1 \\
5 & 18.3 & 18.2 \\
9.9 & 31.2 & 31.9 \\
$10-14$ & & 45 \\
$15-18$ & & 60 \\
$>18$ & & 70 \\
\hline
\end{tabular}

\subsection{DON Exposure in Adolescents and Adults}

In all cases, considering mean DON occurrence levels as a fixed parameter and mean, 95th percentile and 99th percentile consumption rates, the overall exposure of the Italian population sub-groups has to be considered not at risk. For instance, for adolescents, even in the worst case, i.e., $133.3 \mathrm{~g} / \mathrm{d}$ corresponding to the 99th percentile consumption rate - a body weight of $45 \mathrm{~kg}$ corresponding to the subgroup of adolescents aged 10-14 years and a mean DON contamination level of $64.8 \mu \mathrm{g} / \mathrm{kg}$ - the exposure would account for $192 \mathrm{ng} / \mathrm{kg}$ bw/day corresponding to almost one fifth of the TDI. By taking as a reference situation the exposure of adolescents, all the other population subgroups - adults and elderly — accounted for an even lower exposure rate considering approximately similar consumption rates and higher body weights. For instance, for adults with a 99th percentile consumption rate of $156.1 \mathrm{~g} / \mathrm{d}$, a body weight of $70 \mathrm{~kg}$ and considering the DON mean contamination level, the exposure resulted in $144.5 \mathrm{ng} / \mathrm{kg}$ bw/day.

\subsection{DON Intakes in Children}

As far as children, different scenarios for their exposure assessment were taken into consideration consistently with different consumption rates (mean, 95th percentile and 99th percentile) and contamination levels (mean level, threshold level, legal limit) (Table 5). By accounting for the daily mean consumption rate of pasta corresponding to $59.8 \mathrm{~g}$ for children aged from 3 to 9.9 years, the exposure, only related to the consumption of pasta, did not reveal any alarming situation, being quite far below the TDI.

More specifically, the obtained exposure rates decreased from 3 year old children to 10 year old children accounting for a mean value, combining male and female data, of $275 \mathrm{ng} / \mathrm{kg} \mathrm{bw} / \mathrm{day}$ ( $27 \%$ of the TDI) to $123 \mathrm{ng} / \mathrm{kg} / \mathrm{bw} /$ day (12\% of TDI), respectively.

A second scenario was evaluated taking into consideration double the mean contamination level, i.e., $130 \mu \mathrm{g} / \mathrm{kg}$; also in this condition, the exposure equalled $50 \%$ of the TDI in the worst case 
(children aged 3 years). No meaningful difference between male (543 ng/kg bw/day) and female (559 ng/kg bw/day) groups was noted.

A third scenario considering the calculated DON contamination level leading to an exposure corresponding to the TDI for every subgroup of children was also considered. The resulting levels ranged from one third to two third of the legal limit, as set by the Regulation 1126/2007 [25].

Nevertheless, it must be considered that $99 \%$ of the results obtained from this study fell below these contamination levels.

In Table 6, the same scenarios were calculated but for consumption rates corresponding to the 99th percentile, i.e., 161.7 grams. Even in this case, the exposure corresponding to the mean occurrence level obtained in the present study always fell below the TDI with a maximum value for the exposure accounting for the $75 \%$ of the toxicological threshold in the worst case (females aged 3 years).

Table 5. DON exposure in children (males (M) and females (F)) assuming a mean consumption of pasta of $59.8 \mathrm{~g}$ for children aged from 3 to 9.9 years.

\begin{tabular}{|c|c|c|c|c|}
\hline $\begin{array}{c}\text { DON contamination } \\
(\mu \mathrm{g} / \mathrm{kg})\end{array}$ & $\begin{array}{c}\text { Weight (kg) /age } \\
\text { (years) males }\end{array}$ & $\begin{array}{c}\text { Exposure of males } \\
\text { (ng/kg bw/day) }\end{array}$ & $\begin{array}{l}\text { Weight (kg) /age } \\
\text { (years) females }\end{array}$ & $\begin{array}{c}\text { Exposure of females } \\
\text { (ng/kg bw/day) }\end{array}$ \\
\hline \multirow[t]{4}{*}{$64.8^{*}$} & $14.3 / 3$ & 271 & $13.9 / 3$ & 279 \\
\hline & $16.3 / 4$ & 237 & $16.1 / 4$ & 240 \\
\hline & $18.3 / 5$ & 211 & $18.2 / 5$ & 213 \\
\hline & $31.2 / 10$ & 124 & $31.9 / 10$ & 121 \\
\hline \multirow[t]{4}{*}{130} & $14.3 / 3$ & 543 & $13.9 / 3$ & 559 \\
\hline & $16.3 / 4$ & 476 & $16.1 / 4$ & 482 \\
\hline & $18.3 / 5$ & 424 & $18.2 / 5$ & 427 \\
\hline & $31.2 / 10$ & 249 & $31.9 / 10$ & 243 \\
\hline $239(\mathrm{M})-233(\mathrm{~F})$ & $14.3 / 3$ & 999 & $13.9 / 3$ & 1002 \\
\hline $273(\mathrm{M})-269(\mathrm{~F})$ & $16.3 / 4$ & 1001 & $16.1 / 4$ & 999 \\
\hline $306(\mathrm{M})-305(\mathrm{~F})$ & $18.3 / 5$ & 999 & $18.2 / 5$ & 1002 \\
\hline $522(\mathrm{M})-533(\mathrm{~F})$ & $31.2 / 10$ & 1000 & $31.9 / 10$ & 999 \\
\hline
\end{tabular}

Note: *: DON contamination level $(\mathrm{N}=472)$.

Table 6. DON exposure in children (males (M) and females (F)) assuming a 99th percentile consumption of pasta of $161.7 \mathrm{~g}$ for children aged from 3 to 9.9 years.

\begin{tabular}{ccccc}
\hline $\begin{array}{c}\text { DON contamination } \\
(\boldsymbol{\mu g} / \mathbf{k g})\end{array}$ & $\begin{array}{c}\text { Weight } \mathbf{( k g )} / \text { age } \\
\text { (years) males }\end{array}$ & $\begin{array}{c}\text { Exposure of males } \\
\text { (ng//kg bw/day) }\end{array}$ & $\begin{array}{c}\text { Weight (kg) /age } \\
\text { (years) females }\end{array}$ & $\begin{array}{c}\text { Exposure of females } \\
\text { (ng/kg bw/day) }\end{array}$ \\
\hline $64.8^{*}$ & $14.3 / 3$ & 732 & $13.9 / 3$ & 753 \\
& $16.3 / 4$ & 643 & $16.1 / 4$ & 650 \\
& $18.3 / 5$ & 572 & $18.2 / 5$ & 575 \\
& $31.2 / 10$ & 335 & $31.9 / 10$ & 328 \\
$89(\mathrm{M})-86(\mathrm{~F})$ & $14.3 / 3$ & 1006 & $13.9 / 3$ & 1000 \\
$101(\mathrm{M})-100(\mathrm{~F})$ & $16.3 / 4$ & 1002 & $16.1 / 4$ & 1004 \\
$114(\mathrm{M})-113(\mathrm{~F})$ & $18.3 / 5$ & 1007 & $18.2 / 5$ & 1003 \\
$193(\mathrm{M})-198(\mathrm{~F})$ & $31.2 / 10$ & 1000 & $31.9 / 10$ & 1003 \\
\hline
\end{tabular}


Analogously to the previous description of different scenarios, the DON concentration levels leading to an exposure equal to the TDI were calculated resulting in all children subgroups as a higher value than the DON mean contamination level obtained in this study.

A last scenario, shown in Figures 2 and 3, leads to a very challenging issue since if the legal limit of $750 \mu \mathrm{g} / \mathrm{kg}$ is considered, for any consumption rate, both mean and high values (99th percentile), and for all children subgroups, an increase of 1.5-8 times the TDI would be reached, respectively.

Figure 2. DON exposure for a consumption of pasta of $59.8 \mathrm{~g}$ (mean consumption of pasta by children between 3 and 9.9 years old, [45]) at a contamination level of $750 \mu \mathrm{g} / \mathrm{kg}$.

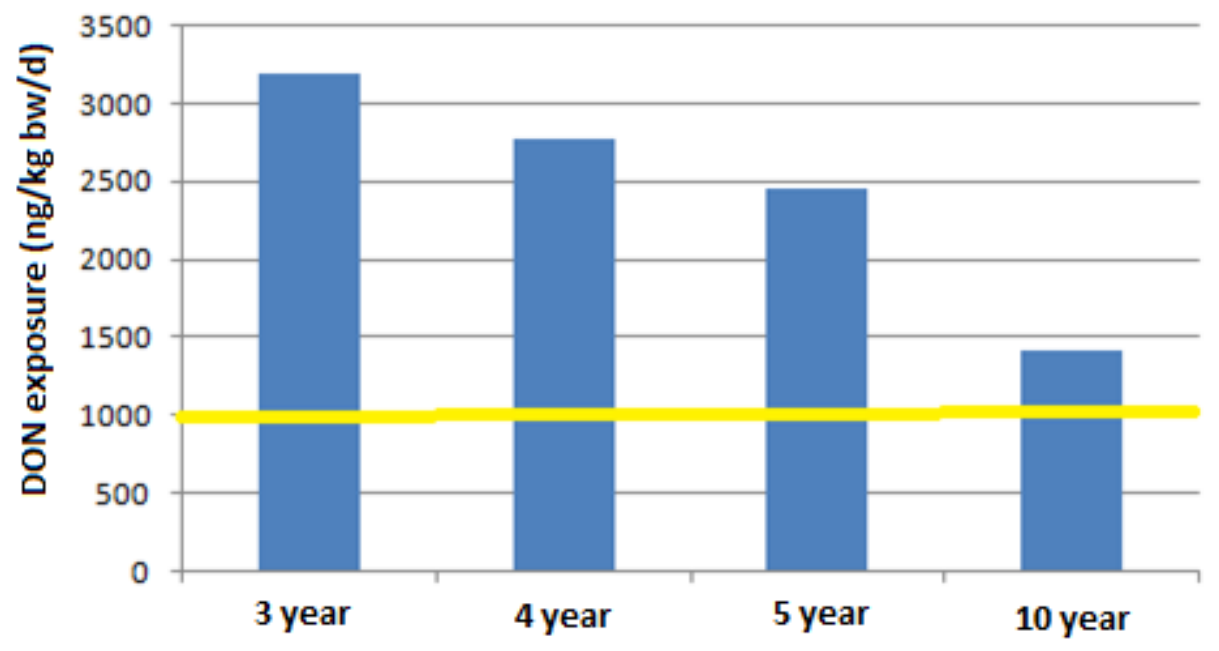

Figure 3. DON exposure for a consumption of pasta of $161.7 \mathrm{~g}$ (99th percentile of consumption of children between 3 and 9.9 years old, [45]) at a contamination level of $750 \mu \mathrm{g} / \mathrm{kg}$.

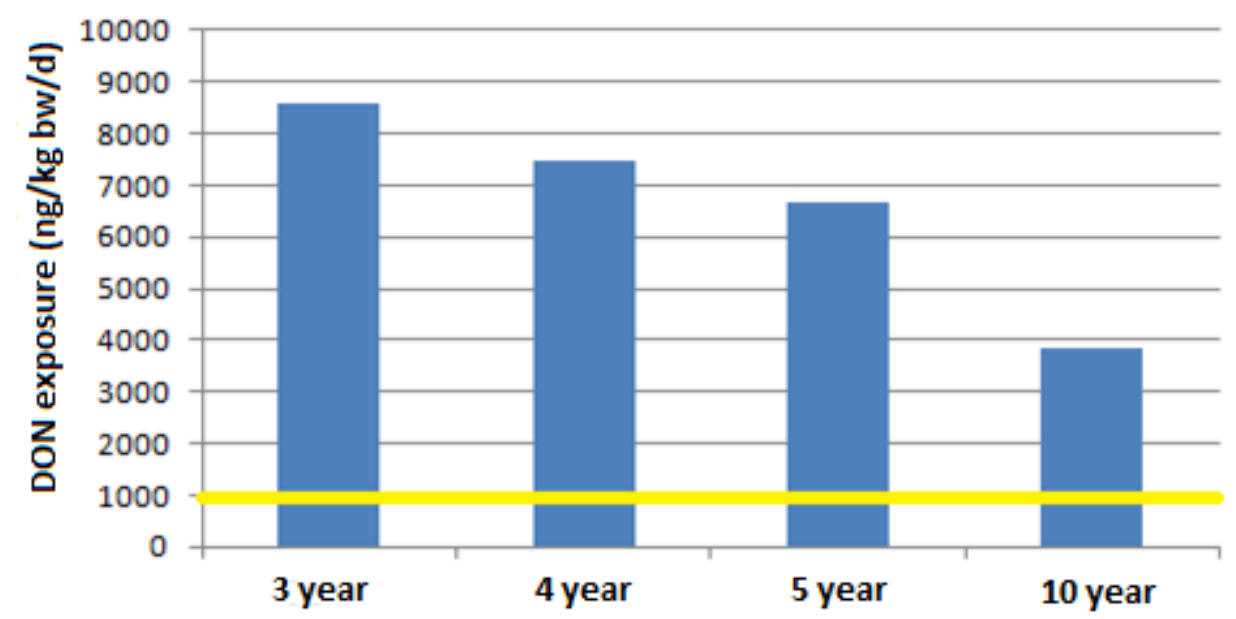

\section{Experimental Section}

\subsection{Sampling}

In order to assess the level of DON contamination in pasta, 472 packages of commercially produced pasta taken from four large-scale retail traders distributed in different geographical areas in Italy were 
collected over a period between November 2010 and May 2011. Pasta samples were chosen with the criterion to guarantee the maximum representativeness of the most diffused marketed and consumed products. The selection was chosen on the basis of the market share and consumption rates in the north, south and centre of Italy. Forty-one brands were sampled.

The collected samples had to meet the following characteristics:

- Typology of pasta products (dry, fresh (10\%), whole (10\%), not egg-pasta, not addressed to baby food chain);

- Random selection among different shape of pasta products (spaghetti, medium size like rigatoni, short size like penne);

- Only one 500 g package per lot, typology, shape and brand.

\subsection{Principle of the Method}

The analytical method used for the analysis of pasta samples got accreditation, number 0779 , by the national accreditation body ACCREDIA, for DON determination in wheat and derived products.

DON is extracted from the matrix by homogenizing the sample with water. After centrifugation, the extract is cleaned-up step by immunoaffinity columns and the toxin is eluted with methanol, dried under nitrogen and re-dissolved in an aqueous solution of methanol (9.5\%). DON is quantified by reversed-phase HPLC by UV detection.

According to the obtained linearity, the used analytical method for DON determination in pasta samples is to be considered applicable in the range $70 \mu \mathrm{g} / \mathrm{kg} \div 2000 \mu \mathrm{g} / \mathrm{kg}$.

\subsection{Sample Preparation}

The first step was to choose between a wet (slurry) and a dry homogenization of pasta samples. The preparation of slurried samples by using a lab-scale 4-lt Waring Blender and adding to the sample tap water in a ratio 1:1, led to very sticky products. For this reason, this approach was abandoned and a processing of samples in dry conditions was preferred.

All pasta samples were ground with a laboratory mill (Retsch ZM 200, Retsch GmbH, Haan, Germany) to obtain a particle size of at least $0.75 \mathrm{~mm}$. After grinding and before drawing the test aliquot, a thorough homogenization of the test portion was done.

\subsubsection{Extraction}

DON is extracted by weighing $20.0 \mathrm{~g}( \pm 0.1 \mathrm{~g})$ of the dry ground test portion directly in the blender. One hundred and sixty milliliters of deionized water as extraction solvent was added. After 3 min of blending, the extract is centrifuged at $8000 \mathrm{rpm}$ per $10 \mathrm{~min}$.

The extract is then transferred to the IAC.

\subsubsection{Immunoaffinity Clean-Up}

To clean samples, manufacturers' instructions of IAC (DONPREP, R-Biopharm-Rhone, Glasgow, UK) were followed. IAC columns were kept at room temperature before the conditioning. 
Under slight vacuum conditions, $3 \mathrm{~mL}$ (equivalent to 0.375 grams of pasta) of the centrifuged extract was pipetted into the syringe connected to the IAC. During the clean-up, the flow was maintained at a constant flow of not more than $3 \mathrm{~mL} / \mathrm{min}$, (in any case, the flow speed must not exceed $5 \mathrm{~mL} / \mathrm{min}$ ).

After the complete passage of the filtered sample, IAC was washed with $5 \mathrm{~mL}$ of de-ionized water. The column was successively dried by flowing at least 2 volumes of air.

DON was eluted from the IAC in two steps: firstly, $750 \mu \mathrm{L}$ of methanol were flown by gravity and then, after $1 \mathrm{~min}$, a second amount of $750 \mu \mathrm{L}$ of methanol was applied to the IAC.

To collect the entire residual methanol, the elution is completed by pushing one volume of air inside the IAC by a $10-\mathrm{mL}$ syringe.

The eluate is taken to dryness with a nitrogen flow at a temperature of $40{ }^{\circ} \mathrm{C}$. The residue is then redissolved in $750 \mu \mathrm{L}$ of the injection mixture $\mathrm{MeOH}: \mathrm{H}_{2} \mathrm{O}(9.5 \%: 90.5 \%$, v:v), and mixed thoroughly by vortex. The sample to be injected was stored at $4{ }^{\circ} \mathrm{C}$ until the HPLC analysis.

\subsection{HPLC Analysis}

One-hundred and fifty microliters (equivalent to 0.075 grams of pasta sample) out of $750 \mu \mathrm{L}$ of the reconstituted analytical sample were injected onto HPLC, by partial loop.

HPLC Operating Conditions

The following operating conditions were used:

- Chromatographic column: Symmetry ${ }^{\circledR}$ C18 (Waters, Milford, Massachusetts, UK) reversed phase, $5 \mu \mathrm{m}, 4.6 \mathrm{~mm} \times 150 \mathrm{~mm}$, kept at constant temperature of $40^{\circ} \mathrm{C}$;

- Mobile phase: deionized water: methanol 85:15 v:v;

- Flow rate: $1.0 \mathrm{~mL} / \mathrm{min}$;

- UV spectrophotometer regulated at a wavelength of $220 \mathrm{~nm}$;

- Injection Volume: $150 \mu \mathrm{L}$.

\subsection{Spiking Procedure}

To assess the recovery factors to be used for correcting the analytical results, six replicates of fortified samples were prepared by weighing directly in the homogenizer $20.0 \mathrm{~g} \pm 0.1 \mathrm{~g}$ of blank pasta samples and pipetting proper volumes of working solution of DON reference standard to obtain spiking concentration levels of $200 \mu \mathrm{g} / \mathrm{Kg}$ and $750 \mu \mathrm{g} / \mathrm{Kg}$. The fortified samples were left under hood for two hours before the successive processing.

\subsection{Validation Study}

With the aim to test the reliability of the analytical results, a single-laboratory validation study was performed on the used method according to the IUPAC protocol [48].

All method performance characteristics, including precision and accuracy, were compliant with the criteria set by the European Commission Regulation (CE) 401/2006 [49]. 


\section{Limit of Quantification}

The limit of quantification (LoQ) of the used method was calculated over replicate analyses of blank samples and calculating mean values and standard deviation of the areas of the background. The standard deviation was then multiplied by 10 .

From this approach a LoQ of $70 \mu \mathrm{g} / \mathrm{kg}$ was calculated. In these analyses, a value of repeatability $\leq 10 \%$ was verified.

\subsection{Calibration Curve}

Fit for purpose calibration curve was built up by preparing six working solutions in 5-mL flasks. Each level was injected in triple.

The stock solution of the primary certified standard material (Trilogy ${ }^{\circledR}, \mathrm{R}-$ Biopharm: $100 \mu \mathrm{g} / \mathrm{mL}$ ) was diluted with a mixture water:methanol 90.5:9.5 (v:v) to $10 \mu \mathrm{g} / \mathrm{mL}$, by pipetting $1000 \mu \mathrm{L}$ of it in $10-\mathrm{mL}$ flask. To prepare working solutions necessary for the building up of the calibration curve, proper amounts of DON were drawn from the diluted solution.

\section{Conclusions}

Estimates of dietary exposure to DON based on the obtained occurrence data in pasta samples are far below the TDI of $1000 \mathrm{ng} / \mathrm{kg} \mathrm{b.w}$. for populations of all age groups, and therefore do not represent a health concern.

Just in some cases regarding population subgroups' exposure to DON, some borderline situations were noted. In fact, considering a DON contamination level slightly higher than the mean value obtained in this study-like for instance $90-100 \mu \mathrm{g} / \mathrm{kg}$, for children from 3 to 5 years with high consumption rates (99th percentile) - the exposure levels would reach the TDI, considering pasta as the only daily contribution to exposure.

However, it should be noted that the abovementioned concentration value would correspond to almost one seventh of the legal limit; therefore, creating a quite challenging situation where even for very low levels of DON contamination in a food product highly consumed such as pasta, a health warning for some sensitive consumer groups could be raised.

It should be also noted that, due to the high DON hydro-solubility, the overall exposure assessment should, however, be re-examined considering a loss of up to $20 \%$ of DON after cooking pasta, except for when the cooking water remains in the meal as in the case of soups, consumed especially by the elderly and young children.

The scientific information derived from this study can provide a basis for more strict consideration of children's exposure through diet, since even for contamination levels far lower than the legal limit, borderline situations can arise.

This consideration is more pertinent if applied to DON that is present in the wide spectrum of food products such as bread, breakfast cereals, pizza, biscuits and other cereal-based products.

For the above, reconsideration both of the maximum tolerable legal limit and of the toxicological threshold could represent interesting and challenging topics to be examined with the aim to guarantee 
an even higher level of safety for those population subgroups, such as children and adolescents, for whom in some cases issues could arise.

\section{Conflicts of Interest}

The authors declare no conflict of interest.

\section{References}

1. Kushiro, M. Effects of milling and cooking processes on the Deoxynivalenol content in wheat. Int. J. Mol. Sci. 2008, 9, 2127-2145.

2. Bretz, M.; Beyer, M.; Cramer, B.; Knecht, A.; Humpf, H.U. Thermal degradation of the Fusarium mycotoxin deoxynivalenol. J. Agric. Food Chem. 2006, 54, 6445-6451.

3. Hazel, C.M.; Scudamore, K.A.; Patel, S.; Scriven, F. Deoxynivalenol and other Fusarium mycotoxins in bread, cake, and biscuits produced from UK-grown wheat under commercial and pilot scale conditions. Food Addit. Contam. 2009, 26, 1191-1198.

4. Payne, G.A. Ear and kernel rots. In Compendium of Corn Diseases; White, D.G., Ed.; The American Phytopathology Society (APS Press): St. Paul, MN, USA, 1999; pp. 44-47.

5. Lawlor, P.G.; Lynch, P.B. Mycotoxins in pig feeds. 2: Clinical aspects. Irish Vet. J. 2001, 54, $172-176$.

6. Cheeke, P.R.; Shull, L.R. Natural Toxicants in Feeds and Poisonous Plants; Avi Publishing Company Inc.: Westport, CT, USA, 1985; p. 492.

7. Prelusky, D.; Rotter, B.; Rotter, R. Toxicology of mycotoxins. In Mycotoxins in Grain: Compounds Other than Aflatoxins; Miller, J., Trenholm, H., Eds.; Eagan Press: St. Paul, MN, USA, 1994; pp. 359-403.

8. Pestka, J.J.; Smolinski, A.T. Deoxynivalenol: Toxicology and potential effects on humans. $J$. Toxicol. Environm. Health Part B 2005, 8, 39-69.

9. Prelusky, D.B.; Veira, D.M.; Trenholm, H.L. Plasma pharmacokinetics of the mycotoxin Deoxynivalenol following oral and intravenous administration to sheep. J. Environ. Sci. Health B 1985, 20, 603-624.

10. Prelusky, D.B.; Hartin, K.E.; Trenholm, H.L.; Miller, J.D. Pharmacokinetic fate of carbon-14-labeled Deoxynivalenol in swine. Fundam. Appl. Toxicol. 1988, 10, 276-286.

11. Pestka, J.J.; Lin, W.S.; Miller, E.R. Emetic activity of the trichothecene 15 acetyldeoxynivalenol in pigs. Food Chem. Toxicol. 1987, 25, 855-858.

12. Prelusky, D.B.; Trenholm, H.L. The efficacy of various classes of anti-emetics in preventing Deoxynivalenol-induced vomiting in swine. Nat. Toxins 1993, 1, 296-302.

13. Canady, R.A.; Coker, R.D.; Egan, S.K.; Krska, R.; Kuiper-Goodman, T.; Olsen, M.; Pestka, J.; Resnik, S.; Schlatter, J. Deoxynivalenol. In Safety Evaluation of Certain Mycotoxins in Food, WHO Food Additive Series 47; World Health Organization: Geneva, Switzerland, 2001; pp. 419-555.

14. Berthiller, F.; Crews, C.; Dall'Asta, C.; Saeger, S.D.; Haesaert, G.; Karlovsky, P.; Oswald, I.P.; Seefelder, W.; Speijers, G.; Stroka, J. Masked mycotoxins: A review. Mol. Nutr. Food Res. 2013 $57,165-186$. 
15. Maresca, M. From the gut to the brain: Journey and pathophysiological effects of the food-associated trichothecene mycotoxin Deoxynivalenol. Toxins 2013, 23, 784-820.

16. Visconti, A. Problems associated with Fusarium mycotoxins in cereals. Bull. Inst. Compr. Agric. Sci. 2001, 9, 39-55.

17. Pestka, J.J. Deoxynivalenol: Mechanisms of action, human exposure, and toxicological relevance. Arch. Toxicol. 2010, 84, 663-679.

18. Pestka, J.J. Deoxynivalenol-induced proinflammatory gene expression: Mechanisms and pathological sequelae. Toxins 2010, 2, 1300-1317.

19. Rocha, O.; Ansari, K.; Doohan, F.M. Effects of trichothecene mycotoxins on eukaryotic cells: A review. Food Addit. Contam. 2005, 22, 369-378.

20. Sobrova, P.; Adam, V.; Vasatkova, A.; Beklova, M.; Zeman, L. Deoxynivalenol and its toxicity. Interdiscip. Toxicol. 2010, 3, 94-99.

21. Rotter, B.A.; Prelusky, D.B.; Pestka, J.J. Toxicology of deoxynivalenol (vomitoxin). J. Toxicol. Environm. Health 1996, 48, 1-34.

22. Sergent, T.; Parys, M.; Garsou, S.; Pussemier, L.; Schneider, Y.J.; Larondelle, Y. Deoxynivalenol transport across human intestinal Caco-2 cells and its effects on cellular metabolism at realistic intestinal concentrations. Toxicol. Lett. 2006, 164, 167-176.

23. FAO. Worldwide Regulations for Mycotoxins in Food and Feed in 2003, Food and Nutrition Paper 81; Food and Agriculture Organization of the United Nations: Rome, Italy, 2003.

24. Proposed draft maximum levels for Deoxynivalenol in cereals and cereal-based products and associated sampling plans (CX/CF 13/7/7). In Proceedings of Codex Committee on Contaminants in Food 7th Session, Moscow, Russian Federation, 8-12 April 2013.

25. European Commission. Commission Regulation (EC) No 1126/2007 of 28 September 2007 amending Regulation (EC) No 1881/2006 setting maximum levels for certain contaminants in foodstuffs as regards Fusarium toxins in maize and maize products. Off. J. Eur. Union 2007, L 255/14.

26. European Commission. Commission Recommendation of 17 August 2006 on the presence of deoxynivalenol, zearalenone, ochratoxin A, T-2 and HT-2 and fumonisins in products intended for animal feeding. Off. J. Eur. Union 2006, L 229/7.

27. Swanson, S.P.; Rood, H.D.; Behrens, J.C.; Sanders, P.E. Preparation and characterization of the deepoxy trichothecenes: deepoxy HT-2, deepoxy T-2 triol, deepoxy T-2 tetraol, deepoxy 15-monoacetoxyscirpenol, and deepoxy scirpentriol. Appl. Environm. Microb. 1987, 53, 2821-2826.

28. Maresca, M.; Fantini, J. Some food-associated mycotoxins as potential risk factors in humans predisposed to chronic intestinal inflammatory diseases. Toxicon 2010, 56, 282-294.

29. Mezzelani, A.; Landini, M.; Facchiano, F.; Raggi, M.E.; Villa, L.; Molteni, M.; De Santis, B.; Brera, C.; Caroli, A.M.; Milanesi, L.; et al. Environment, dysbiosis, immunity, and sex-specific susceptibility: An evidence-based translational hypothesis for regressive autism pathogenesis. Nutr. Neurosci. 2013, submitted for publication.

30. Ueno, Y. The toxicology of mycotoxins. CRC Crit. Rev. Toxicol. 1985, 14, 99-132.

31. Ueno, Y. Toxicology of trichothecene mycotoxins. ISI Atlas Sci. Pharm. 1988, 2, 121-124. 
32. Meky, F.A.; Turner, P.C.; Ashcroft, A.E.; Miller, J.D.; Qiao, Y.L.; Roth, M.J.; Wild, C.P. Development of a urinary biomarker of human exposure to Deoxynivalenol. Food Chem. Toxicol. 2003, 41, 265-273.

33. Pieters, M.N.; Freijer, J.L.; Baars, A.J.; Fiolet, D.C.M.; Van Klaveren, J.; Slob, W. Risk assessment of Deoxynivalenol in food. Concentration limits, exposure and effects. Adv. Exp. Med. Biol. 2002, 504, 235-248.

34. Turner, P.C.; Rothwell, J.A.; White, K.L.M.; Cade, J.E.; Wild, C.P. Urinary Deoxynivalenol is correlated with cereal intake in individuals from the United Kingdom. Environ. Health Persp. 2008, 116, 21-25.

35. Hepworth, S.J.; Hardie, L.J.; Fraser, L.K.; Burley, V.J.; Mijal, R.S.; Wild, C.P.; Azad, R.; McKinney, P.A.; Turner, P.C. Deoxynivalenol exposure assessment in a cohort of pregnant women from Bradford, UK. Food Addit. Contam. Part A 2012 29, 269-276.

36. Collection of OCCURRENCE DATA of Fusarium TOXIns in FOod and ASSESSment of DIETARY INTake by the POpulation of EU Member States, Scientific Cooperation (SCOOP) 3.2.10.; Directorate General Health and Consumer Protection: Brussels, Belgium, 2003.

37. Larsen, J.C.; Hunt, J.; Perrin, I.; Ruckenbauer, P. Workshop on trichothecenes with a focus on DON: Summary report. Toxicol. Lett. 2004, 153, 1-22.

38. Pietri, A.; Bertuzzi, T.; Zanetti, M.; Rastelli, S. Presenza di tricoteceni e di ocratossina A in baby-foods e prodotti dietetici ricchi di crusca. In Rapporti ISTISAN 05/42; Miraglia, M., Carlo, B., Eds.; Istituto Superiore di Sanità: Rome, Italy, 2005; pp. 39-42.

39. Brera, C.; Peduto, A.; Debegnach, F.; Pannunzi, E.; Prantera, E.; Gregori, E.; De Giacomo, M.; De Santis, B. Study of the influence of the milling process on the distribution of Deoxynivalenol content from the caryopsis to cooked pasta. Food Control 2012, 32, 309-312.

40. Visconti, A.; Haidukowski, M.; Pascale, M.; Silvestri, M. Reduction of Deoxynivalenol during durum wheat processing and spaghetti cooking. Toxicol. Lett. 2004, 153, 181-189.

41. Raiola, A.; Meca, G.; Mañes, J.; Ritieni, A. Bioaccessibility of Deoxynivalenol and its natural co-occurrence with Ochratoxin A and Aflatoxin B1 in Italian commercial pasta. Food Chem. Toxicol. 2012, 50, 280-287.

42. González-Osnaya, L.; Cortés, C.; Soriano, J.M.; Moltó, J.C.; Mañes, J. Occurrence of Deoxynivalenol and T-2 toxin in bread and pasta commercialised in Spain. Food Chem. 2011, 124, 156-161.

43. Bockhorn, I.; Bockhorn, A.; Pohler, S. Deoxynivalenol (DON) in raw and cooked pasta. Mycotoxin Res. 2001, 17 (Suppl. 1), 67-70.

44. SCF (Scientific Committee on Food). Opinion of the Scientific Committee on Food on Fusarium toxins. Part 6: Group Evaluation of T-2 Toxin, HT-2 Toxin, Nivalenol and Deoxynivalenol: SCF/CS/CNTM/MYC/27 Final. 2002. Available online: http://europa.eu.int/comm/food/fs/sc/ scf/out123_en.pdf (accessed on 15 June 2007).

45. Leclercq, C.; Arcella, D.; Piccinelli, R.; Sette, S.; Le Donne, C.; Turrini, A. The Italian National Food Consumption Survey INRAN-SCAI 2005-06: Main results in terms of food consumption. Public Health Nutr. 2009, 12, 2504-2532.

46. World Health Organization (WHO). Child Growth Standards. Available online: http://www.who.int/childgrowth/standards/en/ (accessed on 21 November 2013). 
47. European Food Safety Authority (EFSA). Scientific opinion-Guidance on selected default values to be used by the EFSA Scientific Committee, Scientific Panels and Units in the absence of actual measured data. EFSA J. 2012, 10, 2579-2611.

48. Thompson, M.; Ellison, S.L.R.; Wood, R. Harmonized guidelines for single-laboratory validation of methods of analysis (IUPAC Technical Report). Pure Appl. Chem. 2002, 74, 835-855.

49. European Commission. Commission Regulation (EC) No 401/2006 of 23 February 2006 laying down the methods of sampling and analysis for the official control of the levels of mycotoxins in foodstuffs. Off. J. Eur. Union 2006, L70/1.

(C) 2013 by the authors; licensee MDPI, Basel, Switzerland. This article is an open access article distributed under the terms and conditions of the Creative Commons Attribution license (http://creativecommons.org/licenses/by/3.0/). 